\title{
ETHICAL CONSIDERATIONS IN RESEARCH WITH CHILDREN
}

\author{
Shahanaz Chowdhury \\ Assistant Professor, Department of Community Medicine, \\ Bangladesh University of Health Science, Dhaka, Bangladesh \\ Email: jesmin_70@yahoo.com
}

\begin{abstract}
Ethical concerns and medical advances unique to children and adolescents make pediatric research an evolving endeavor. The current regulations for clinical research are based on a combination of ethical thought and history, some of it being very tragic. This article presents the ethical and historical underpinnings of these regulations, including elaborative discussion on ethical standards in research. In addition, the article highlights that every effort should be made to actively involve children as participants in the research process and care must be taken to protect the rights of all children, as well as specific groups of children, in research activity.
\end{abstract}

key words: rights of all children, regulations for clinical research, ethical standards in research and pediatric research.

HISTORICAL BACKGROUND: The historical origin of current ethical principles for conducting research with children arises from the Nuremberg Trials, which took place after the Second World War, the Code, which emerged from these is called Nuremberg Code. The code sets out statements of certain moral, ethical and legal principles relating to research involving human subjects. "Taken literally, research on children would be prohibited. Requires the voluntary consent of the subject "as absolutely essential" Later, the emergence of the Declaration of Helsinki in 1964, most recently amended in 1989 and 1996, now includes and examination of the issues of children as research subjects relation to informed consent ${ }^{1}$.

The ethics of research with children is a balance. On the one hand, the focus is on ways of preventing and reducing harms in research and ensuring adequate protection of children and young people. On the other hand, there is concern about the risks and harms of silencing and excluding children from research about their views, experiences and participation.

There are, however, ongoing debates in the academic literature about the ethics of social research with children, related to different disciplinary perspectives (for example, developmental psychology and the sociology of childhood) and in relation to the differences between children and adults in research. The ethics principles that apply to research with adults - such as that of ensuring freely given fully informed consent, and the right to withdraw from research participation - apply equally to children, but there are four additional provisos specific to research involving children:

i. children's competencies, perceptions and frameworks of reference, which may differ according to factors including - but not only - their age, may differ from those of adults;

ii. children's potential vulnerability to exploitation in interaction with adults, and adults' specific responsibilities towards children; 
iii. the differential power relationships between adult researcher and child participant; and

iv. the role of adult gatekeepers in mediating access to children, with concomitant ethical implications in relation to informed consent ${ }^{2}$.

INTRODUCTION: 'Ethics' can be defined as 'set of moral principles and rules of conduct'. Ethics in research, as one author has put it, relates to 'the application of a system of moral principles to prevent harming or wrong doing others, to promote the good, to be respectful, and to be fair ${ }^{3}$ Ethics is a core consideration to most research. This is especially true for research that involves children where there will have to be a balance between the researcher's aims and the protection of any participants. Involving children in research can enhance the scope and findings of a study. The United Nations Convention on the Rights of the Child is often used as a basis for the need to actively involve children in research, especially when that research may be used to inform and influence policy makers: "States Parties shall assure to the child who is capable of forming his or her own views the right to express those views freely in all matters affecting the child, the views of the child being given due weight in accordance with the age and maturity of the child. There are some key concepts that should be considered by all researchers who hope to include children in their research, namely: obtaining informed consent; managing the risk of further harm to the child; and, managing what happens to the information given by participants ${ }^{4}$. More recently, pediatric research has come to be seen as a moral imperative ${ }^{5}$.

METHODS: This is a review article done during the participation in the educational activity of National Institutes of Health Bethesda, Maryland held by Bangladesh Bioethics Society through video conferencing on September 25, 2013 through November 11, 2013. The search was confined to Google search and pubmed published articles.

\section{ETHICAL STANDARDS IN RESEARCH ${ }^{6}$}

Research ethics are a set of principles about how researchers and research organizations should conduct themselves when dealing with research participants, other researchers and colleagues, the users of their research and society in general. Particularly relevant to the social sciences are ethics associated with projects involving human participants, including conducting surveys, focus groups and the use of secondary data.

Principle 1. Non-harmful procedures: The investigator should use no research procedure that may harm the child either physically or psychologically. The investigator is also obligated at all times to use the least stressful research procedure whenever possible. Psychological harm in particular instances may be difficult to define; nevertheless, its definition and means for reducing or eliminating it remain the responsibility of the investigator. When the investigator is in doubt about the possible harmful effects of the research procedures, consultation should be sought from others. When harm seems inevitable, the investigator is obligated to find other means of obtaining the information or to abandon the research. Instances may, nevertheless, rise in which exposing the child to stressful conditions may be necessary if direct diagnostic or therapeutic benefits to the child are associated with the research. In such instances careful deliberation by an Institutional Review Board should be sought. 
Principle 2. Informed consent: Before seeking consent or assent from the child, the investigator should inform the child of all features of the research that may affect his or her willingness to participate and should answer the child's questions in terms appropriate to the child's comprehension. The investigator should respect the child's freedom to choose to participate in the research or not by giving the child the opportunity to give or not give assent to participation as well as to choose to discontinue participation at any time. Assent means that the child shows some form of agreement to participate without necessarily comprehending the full significance of the research necessary to give informed consent. Investigators working with infants should take special effort to explain the research procedures to the parents and be especially sensitive to any indicators of discomfort in the infant. In spite of the paramount importance of obtaining consent, instances can arise in which consent or any kind of contact with the participant would make the research impossible to carry out. Non-intrusive field research is a common example. Conceivably, such research can be carried out ethically if it is conducted in public places, participants' anonymity is totally protected, and there are no foreseeable negative consequences to the participant. However, judgments on whether such research is ethical in particular circumstances should be made in consultation with an Institutional Review Board.

Principle 3. Parental consent: The informed consent of parents, legal guardians or those who act in loco parentis (e.g., teachers, superintendents of institutions) similarly should be obtained, preferably in writing. Informed consent requires that parents or other responsible adults be informed of all the features of the research that may affect their willingness to allow the child to participate. This information should include the profession and institution affiliation of the investigator. Not only should the right of the responsible adults to refuse consent be respected, but also they should be informed that they may refuse to participate without incurring any penalty to them or to the child.

Principle 4. Additional consent: The informed consent of any persons, such as schoolteachers for example, whose interaction with the child is the subject of the study should also be obtained. As with the child and parents or guardians informed consent requires that the persons interacting with the child during the study be informed of all features of the research which may affect their willingness to participate. All questions posed by such persons should be answered and the persons should be free to choose to participate or not, and to discontinue participation at any time.

Principle 5. Incentives: Incentives to participate in a research project must be fair and must not unduly exceed the range of incentives that the child normally experiences. Whatever incentives are used, the investigator should always keep in mind that the greater the possible effects of the investigation on the child, the greater is the obligation to protect the child's welfare and freedom.

Principle 6. Deception: Although full disclosure of information during the procedure of obtaining consent is the ethical ideal, a particular study may necessitate withholding certain information or deception. Whenever withholding information or deception is judged to be essential to the conduct of the study, the investigator should satisfy research colleagues that such judgment is correct. If withholding information or deception is practiced, and there is reason to believe that the research participants will be negatively affected by it, adequate measures should be taken after the study to ensure the participant's understanding of the reasons for the deception. Investigators whose research is dependent upon deception should make an effort to employ deception methods that have no known negative effects on the child or the child's family. 
Principle 7. Anonymity: To gain access to institutional records, the investigator should obtain permission from responsible authorities in charge of records. Anonymity of the information should be preserved and no information used other than that for which permission was obtained. It is the investigator's responsibility to ensure that responsible authorities do, in fact, have the confidence of the participant and that they bear some degree of responsibility in giving such permission. In complying with requirements for data sharing, researchers need to carefully consider whether they have provided data which, if combined, risks violating participant anonymity.

Principle 8. Mutual responsibilities: From the beginning of each research investigation, there should be clear agreement between the investigator and the parents, guardians or those who act in loco parentis, and the child, when appropriate, that defines the responsibilities of each. The investigator has the obligation to honor all promises and commitments of the agreement.

Principle 9: Jeopardy: When, in the course of research, information comes to the investigator's attention that may jeopardize the child's well-being, the investigator has a responsibility to discuss the information with the parents or guardians and with those expert in the field in order that they may arrange the necessary assistance for the child. Researchers need to be aware that they may obtain findings suggesting that a child's health and well-being might be in jeopardy, that these findings may include false positives, and they should be knowledgeable about current human subjects procedures and regulations for informing families of incidental findings.

Principle 10. Unforeseen consequences: When research procedures result in undesirable consequences for the participant that were previously unforeseen, the investigator should immediately employ appropriate measures to correct these consequences, and should redesign the procedures if they are to be included in subsequent studies.

Principle 11. Confidentiality: The investigator should keep in confidence all information obtained about research participants. The participants' identity should be concealed in written and verbal reports of the results, as well as in informal discussion with students and colleagues. When a possibility exists that others may gain access to such information, this possibility, together with the plans for protecting confidentiality, should be explained to the participants as part of the procedure of obtaining informed consent.

Principle 12. Misconception: Immediately after the data are collected, the investigator should clarify for the research participant any misconceptions that may have arisen. The investigator also recognizes a duty to report general findings to participants in terms appropriate to their understanding. Where scientific or humane values justify withholding information, every effort should be made so that withholding the information has no damaging consequences for the participant.

Principle 13. Reporting results: Because the investigator's words may carry unintended weight with parents and children, caution should be exercised in reporting results, making evaluative statements, or giving advice. In some kinds of investigation the giving of advice is ethical if this forms an intrinsic part of the research, is agreed with the participant and has been subject to ethics review in advance. In other circumstances, however, a researcher may obtain evidence suggesting the existence of psychological or physical problems of which a participant may appear to 
be unaware. In such a case, the investigator has a responsibility to discuss this with the participant if the investigator believes that by not doing so the participant's future wellbeing may be endangered. Where there is an identified risk of such evidence emerging it is good practice to prepare a protocol in advance and establish an appropriate referral route. If, in the normal course of psychological research, or as a result of problems detected as above, a participant asks for advice about educational, personality, behavioural or health issues, caution should be exercised. If the issue is serious and the investigator is not competent to offer assistance, the appropriate source of professional advice should be recommended. ${ }^{7}$

Principle 14. Implications of findings: Investigators should be mindful of the social, political and human implications of their research and should be especially careful in the presentation of findings from the research. This principle, however, in no way denies investigators the right to pursue any area of research or the right to observe proper standards of scientific reporting.

Principle 15. Scientific misconduct: Misconduct is defined as the fabrication or falsification of data, plagiarism, misrepresentation, or other practices that seriously deviate from those that are commonly accepted within the scientific community for proposing, conducting, analyzing, or reporting research. It does not include unintentional errors or honest differences in interpretation of data. The Society shall provide vigorous leadership in the pursuit of scientific investigation that is based on the integrity of the investigator and the honesty of research and will not tolerate the presence of scientific misconduct among its members. It shall be the responsibility of the voting members of Governing Council to reach a decision about the possible expulsion of members found guilty of scientific misconduct.

Principle 16. Personal misconduct: Personal misconduct that results in a criminal conviction of a felony may be sufficient grounds for a member's expulsion from the Society. The relevance of the crime to the purposes of the Society should be considered by the Governing Council in reaching a decision about the matter. It shall be the responsibility of the voting members of Governing Council to reach a decision about the possible expulsion of members found guilty of personal misconduct.

DIFFERENT RESEARCH METHODS: There are three main kinds of research that can involve children or child protection issues.

- Asking children about their feelings, opinions and experiences. This can be done either in face to face interviews with children or by questionnaire. Data can also be gathered by asking parents about their children's experiences.

- Observing children's behavior. Using monitored experiments or activities or observing children in an uncontrolled environment to see how they react during specific situations.

- Analyzing information contained in files about children (for example, social care case records, serious case reviews, schools records) ${ }^{4}$.

CONCLUSION: In recognition of the benefits of pediatric research, research ethics has evolved from position of excluding children to one of cautious advocacy-acknowledging the critical role of pediatric research, but accompanied 
by careful consideration of the scientific context, evaluation of risks and benefits, and protection to participants. Many countries have adopted regulations or guidelines to protect children in research. Typically, this requires a careful analysis of the risk associated with cleach intervention and/or procedure, and evaluation of potential benefits, provisions for child assent, and ensuring adequate parent/guardian permission. The regulatory agencies overseeing pediatric research need to make a careful ethical assessment weighing sometimes complex trade-offs $\mathrm{s}$ as to protect children's welfare and prevent undue risk of harm while generating scientifically valuable information to answer important questions concerning the health and welfare of children ${ }^{8}$.

Research with, and for, children (defined in Ireland as people below the age of 18) is necessary and beneficial, but particular ethical concerns arise in relation to children's involvement in research and these must be addressed. Basic ethical principles apply to all research and these include a commitment to the well-being, protection and safety of participants; a duty to respect the rights and wishes of those involved; a responsibility to conduct high-quality scientific research; and a commitment to disseminate and communicate the results to stakeholders. In addition to core ethical principles, research with children requires that legal and policy commitments in relation to children, especially national and international child protection policies and guidelines, are adhered to and that a child-centred, inclusive approach to research is adopted. Parental/guardian consent is required for a child to participate in research, but good practice also requires the child's agreement or assent. Confidentiality is key to research practice, but a limitation exists in child-related research if a child protection issue arises and this restriction in relation to confidentiality must be explained when obtaining consent. To ensure child protection, research with children should be carried out in accordance with Children First: National Guidance for the Protection and Welfare of Children and research organizations should have a child protection policy in place, as well as a designated liaison person or member of staff responsible for the implementation of this policy. Every effort should be made to actively involve children as participants in the research process and care must be taken to protect the rights of all children, as well as specific groups of children, in research activity ${ }^{9}$.

\section{References:}

1. Anne Greig and Jane Tylo. Doing Research with children (Sage Publication) 1999 p.148.

2. Research with children. http://www.ethicsguidebook.ac.uk/Research-with-children-105. (access date:12/11/13)

3. Sieber, J. 'The ethics and politics of sensitive research' in Renzetti C \& Lee R M (eds) Researching sensitive topics, London: Sage.14.1993.

4. Conducting safe and ethical research with children http://www.nspcc.org.uk/Inform/research/briefings/ethical-research-factsheet_wda97712.html (access date:12/11/13)

5. Shaddy RE, Denne SC (2010) Clinical report--Guidelines for the ethical conduct ofstudies to evaluate drugsin pediatric populations. Pediatrics 125 (4):850-860.doi:peds.2010-0082 [pii] 10.1542/peds.2010-0082. (access date:12/11/13)

6. Ethical Standards in Research. http://www.srcd.org/about-us/ethical-standards-research. (access date:12/11/13)

7. Code of Human Research Ethics. http://www.bps.org.uk/sites/default/files/documents/code_of_human_research_ethics.pdf 
8. Ethical considerations in conducting pediatric research.

http://www.fda.gov/downloads/AdvisoryCommittees/Committees Meeting

Materials/PediatricAdvisoryCommittee/UCM254315.pdf. (access date:12/11/13)

9. Guidance for developing ethical research projects involving children

http://www.dcya.gov.ie/documents/Publications/Ethics_Guidance.pdf. (access date:12/11/13) 